\section{LA PERCEPCIÓN DEL ESPACIO URBANO. EL APORTE DE LOS MAPAS PERCEPTIVOS AL ANÁLISIS DEL BARRIO ZEN DE PALERMO (ITALIA) ${ }^{1}$}

\author{
Elizabeth Zenteno Torres ${ }^{2}$
}

\section{Resumen}

El barrio ZEN (Zona Espansione Nord) de Palermo representa en el imaginario social italiano un espacio urbano sinónimo de marginalidad y exclusión, de tráfico de drogas, mafia, violencia y comportamientos desviados. En este trabajo analizamos la percepción del espacio urbano que tienen los residentes de este barrio. Para ello se utilizan mapas perceptivos, que permiten conocer su representación visual y subjetiva. Los mapas perceptivos constituyen un complemento para la entrevista, ya que hacen emerger aquella dimensión subjetiva del espacio urbano que es difícil expresar con palabras. Al dibujar, el entrevistado expresa su subjetividad, su interpretación del barrio, que es de fundamental importancia para la investigación social.

\section{PERCEPTIONS ABOUT THE URBAN SPACE. THE CONTRIBUTION OF PERCEPTIVE MAPS TO THE ANALYSIS OF ZEN, PALERMO (ITALY) ${ }^{1}$}

\author{
Elizabeth Zenteno Torres ${ }^{2}$
}

\section{Abstract}

For Italians, the ZEN area (Zona Espansione Nord), Palermo, is an urban space associated with marginality and exclusion, drug trafficking, mafia, violence and deviant behavior. This paper analyzes the perception of ZEN residents about their urban space. To this end, different perceptive maps are used in order to identify visual and subjective representations as they enable the emergence of personal views about the urban space that are difficult to express in words. When drawing, respondents express their individual opinions and depict their neighborhood; these being critical for social research. 
En este sentido los mapas perceptivos han permitido visualizar gráficamente la fragmentación del espacio urbano, que se expresa en diversos niveles. Además identifican ciertas infraestructuras del barrio que constituyen elementos de referencia. Se distinguen también diferencias en la percepción según nivel de educación.

Entonces el presente documento da cuenta de la dimensión subjetiva del espacio urbano y abre la reflexión en torno a la necesidad de explorar metodologías que permitan captar esta dimensión subjetiva de la ciudad en su compleja individualidad; y pone en valor su importancia para el estudio de los fenómenos urbanos.

\section{PALABRAS CLAVE: PERCEPCIÓN, MAPAS, SUBJETIVIDAD, ESPACIO URBANO, PERIFERIAS.}

Recibido: 01-03-2017

Aceptado: 12-12-2017
In this way perceptive maps enable the graphical visualization of the fragmentation experienced by the urban space, which is expressed at different levels. They also identify certain infrastructures that serve as benchmarks and different types of perception that vary according to the level of educational achievement of respondents.

This paper addresses the subjective dimension about the urban space and encourages us to reflect on the need to explore different methodologies to understand the complex individualities underlying this subjective dimension; it also acknowledges the important role of subjectivity within the study of urban phenomena.

KEYWORDS: PERCEPTION, MAPS, SUBJECTIVITY, URBAN SPACE, PERI-URBAN AREAS.

Received: 01-03-2017

Accepted: 12-12-2017

1 This paper is part of the doctoral thesis entitled "Experiencing Segregation on a Daily Basis: The Case of ZEN, Palermo and Paraisopolis, Sao Paulo", presented at the Department of Social Sciences, Sapienza University of Rome.

2 Chile. Academic, Department of Sociology and Researcher at the Social Participation and Territory Observatory, University of Playa Ancha. ORCID https://orcid.org/0000-0001-8220-1823. Email: elizabeth.zenteno@upla.cl. 


\section{Introducción}

Palermo es la capital de la región de Sicilia y la quinta ciudad más poblada de Italia, con cerca de setecientos mil habitantes. Al mismo tiempo es una de las principales capitales del sur, donde se conjugan diversos problemas del llamado mezzogiorno ${ }^{3}$ italiano. En el contexto de una ciudad y una región desventajada en relación al contexto nacional es que se ubica un barrio en el que se manifiestan una serie de problemas sociales, configurando una situación de alta exclusión social.

El barrio ZEN (Zona Espanzione Nord, por su sigla en italiano) es uno de los espacios urbanos de peor reputación en Italia, reconocido en el imaginario social como representante de los males atribuidos a las ciudades del sur del país. Su construcción se propone para contrarrestar el aumento de la demanda de vivienda debido al acelerado crecimiento de la población en los años sesenta. Así, en 1966 comienza la construcción de un conjunto de viviendas sociales en la periferia norte de la ciudad, entre ellos el barrio ZEN a diez kilómetros del centro. Sin embargo, a dos años de iniciada la construcción y aún sin finalizar las viviendas, ocurre un terremoto que destruye el centro histórico

3 El mezzogiorno o el meridión italiano hace referencia a las regiones al sur de Roma, las regiones de Abruzzo, Basilicata, Calabria, Campania, Molise, Puglia, además de las islas Sardegna y Sicilia. Son regiones que, comparativamente, han tenido una menor industrialización y desarrollo económico. de la ciudad. Ante la emergencia, el prefecto de $\mathrm{Pa}$ lermo autoriza, de forma provisoria, la ocupación de las viviendas del naciente barrio ZEN por parte de las familias afectadas, otorgándose dicha autorización aun cuando la mayor parte de las viviendas estén sin conexión a la red vial, de agua potable, de alcantarillado.

Transcurrido el periodo de autorización, los habitantes no abandonaron las viviendas cedidas -ya que era la única solución habitacional con la que contaban-, pasando a ser ocupantes ilegales de las viviendas. A cuatro años del terremoto, en 1972, se realizó una regularización que asigna la propiedad de las viviendas a los efectivos habitantes, a partir de lo cual se han podido regularizar todos los servicios urbanos propios de la 'ciudad formal'.

Paralelamente a este proceso, en 1970 el IACP (Istituto Autonomo di Case Popolari, ente que administra las viviendas sociales) abre un concurso para la realización de una segunda etapa del conjunto de viviendas, que es llamada ZEN 2. La construcción comienza en 1980, sin embargo, los edificios nunca fueron terminados, ya que las viviendas sin concluir fueron ocupadas ilegalmente por familias sin casa. Tal como en el caso anterior, las viviendas quedaron sin conexión a los servicios de agua 
potable, de alcantarillado, sin pavimentación y en total estado de abandono. En definitiva, en una completa falta de servicios que son fundamentales para la vida en ciudad. Sin embargo, para la segunda parte del barrio ZEN no ha habido un proceso efectivo de regularización de la propiedad, por lo que la mayor parte de las viviendas del barrio ZEN 2 aún se mantiene en la ilegalidad.

La Región siciliana elaboró diversas leyes de regularización para este último barrio. La primera, en 1992, permitía la regularización jurídica de los residentes que habían ocupado las viviendas antes del 31 de diciembre de 1991. Sin embargo, la ley fue un intento fallido, ya que solo 490 residentes regularizaron su situación, la cual no varió con la extensión del plazo. En 2005 una nueva ley condicionó el traspaso de la propiedad a la regularización de los servicios hídricos y eléctricos, constituyendo esta un impedimento adicional dada su difícil aplicación.

En el año 2009 el Comune di Palermo ${ }^{4}$, en conjunto con el Istituto Autonomo di Case Popolari (IACP) y la empresa de Servicio de Aguas llevaron a cabo un proyecto de conexión al servicio hídrico de cada una de las residencias, con el fin de facilitar la obtención del contrato con la empresa hídrica. Pero el proyecto se realizó efectivamente en solo un edificio, incluyendo a 188 viviendas, de las cuales sólo 15 firmaron el contrato con la empresa. En la actualidad, de un total de 2.901 viviendas solamente el 15\% (435) cuenta con contrato regular con el IACP y el 17\% (492) está en fase de regulación. El 68\% restante (1.974) de las viviendas es ocupada sin título de propiedad.

En este sentido, la ilegalidad no está representada solamente en la propiedad de la vivienda, sino también en la distribución de los servicios básicos: "la mafia se sustituye al Estado erogando agua y electricidad que roba a la Municipalidad y vende a los privados, obviamente a bajo precio" (Leone, 2008, p. 275). La conexión a la red pública de agua potable ocurre solo en el caso de que el residente, por su propia iniciativa, prefiera regularizar su situación y dejar de pagarle a la mafia local la distribución del agua, para lo cual, además, deberá superar una serie de impedimentos burocráticos. En cuanto a la red eléctrica, la ilegalidad es mucho mayor, ya que no ha habido ningún proceso administrativo que facilite el traspaso a la legalidad.

Otro elemento relevante a considerar respecto a la situación del barrio es la falta de información actualizada en relación a esta parte de la población, la cual data desde hace más de 15 años. Según el censo de 2001 el barrio contaba con una población total de 14.712 habitantes. Pero informaciones no oficiales estiman que en realidad la población es

4 Es el gobierno local, como la Municipalidad o el Ayuntamiento. 
muy superior, con cerca de 40.000 mil habitantes entre ZEN 1 y ZEN 2. En las estadísticas oficiales del barrio hay un enorme vacío y carencia es el primer signo del abandono y desinterés en que vive el barrio, ya que no permite a las respectivas autoridades tener una idea real de los problemas que atraviesa.

"El barrio está habitado en gran parte por jubilados, desempleados de largo tiempo, trabajadores socialmente útiles ${ }^{5}$, jóvenes en edad escolar. El barrio ZEN es un enclave social marginal, receptáculo del lumpen de la ciudad, invisibles a los datos oficiales" (Fava, 2012, p. 80).

De hecho han sido investigaciones universitarias las que han aportado al conocimiento del territorio. Entre ellas destaca la investigación de Fava, para quien los verdaderos problemas se pierden en el silencio de los datos oficiales.

\section{LOCALIZACIÓN DEL BARRIO ZEN}

El barrio está localizado en la periferia norte de la ciudad. Alrededor del barrio ZEN se yuxtaponen diversos modos de habitar, muchos de los cuales son diametralmente opuestos a las viviendas sociales. En el entorno se han erigido grandes viviendas unifamiliares, con jardines y piscinas, pero también con escasos servicios públicos. Es decir, el sector colinda con una zona residencial de clase medio-alta. A pesar de la cercanía entre el barrio clase medio-alta y el barrio vivienda social no existe un diálogo que permita contrarrestar la exclusión social del segundo.

Distintos factores se han conjugado para fragmentar y separar el barrio ZEN de la ciudad. Entre ellos se cuentan las modificaciones en la estructura vial, que incluyen la construcción de una autopista, una circunvalación y una calle provincial. En la práctica, estas modificaciones han ido cercando y recluyendo el barrio ZEN. Las construcciones seguramente han facilitado la conexión entre el centro urbano y el aeropuerto, pero han ido formando progresivamente un terreno fracturado, desconectado de la ciudad. Mela (2010) menciona que esta es una tendencia de algunas ciudades italianas, con un centro hegemónico y otras áreas periféricas, subordinadas y dependientes del desarrollo económico del centro; conformando así una ciudad dual, dividida entre zonas bien integradas a los servicios y, por el contrario, zonas aisladas, emarginadas.

5 Los trabajadores socialmente útiles es una figura jurídica italiana que constituye una categoría especial de trabajadores en situación de desventaja. Esta categorización favorece su inserción en el mercado del trabajo, especialmente para desarrollar empleos públicos que requieren baja cualificación. 
A través de los años el barrio se ha convertido en el lugar símbolo de la degradación urbana, así como del fracaso de la política pública. La imagen externa es aquella de la acumulación de todos los males asociados a los barrios populares: degradación, comportamientos mafiosos y desviados. En cierto modo, el territorio manifiesta este tipo de problemas, especialmente si se compara con la realidad del norte de Italia, sin embargo, los medios de comunicación se han encargado de difundir y alimentar aquella idea, contribuyendo ampliamente a crear la imagen de este 'monstruo' que es hoy ZEN: verdadero 'infierno en la tierra', sinónimo de exclusión, de homogeneidad, de extrañeza, de hostilidad, de comportamientos terriblemente violentos (Fava, 2008).

"Las personas de afuera, lamentablemente, ya que no están aquí en el ZEN, nos consideran a todos iguales. Si aquella es prostituta y vive en el ZEN, somos considerados todos iguales, por la misma cosa... A mí me gustaría hacer entender a las personas que no somos todos iguales, que no somos la misma cosa, no estamos hechos de la misma pasta" (Salvezza, 45 años, residente).

Como lo han indicado los investigadores Fava (2008) y Picone (2012), aunque los palermitanos escasamente sepan ubicar el barrio en un mapa identifican perfectamente la imagen de los habitantes de ZEN que se ha reproducido por decenios en los medios de comunicación:
"Las mujeres dueñas de casa narcotraficantes y prostitutas, los niños son baby-narcos pagados por la mafia, los hombres son ladrones, cesantes empedernidos e indolentes o empleados que no son de fiar. Sus actividades recurrentes se reducen, en gran parte, a las ocupaciones ilegales y al crimen callejero, a comportamientos contrarios a la moral y a las costumbres ya extrañas en la modernidad dominante. Esta generalización equivale a su categorización, es decir a su 'acusación pública'" (Fava, 2008, p. 54).

Así, en el imaginario social de Palermo los habitantes del barrio ZEN constituyen 'los otros', en términos de Augé (2008), aquellos que, aunque parte de una misma ciudad, viven en un territorio donde solo 'los otros' pueden entrar. Y es que, efectivamente, dentro el barrio no hay algo que eventualmente haga 'entrar' a los ciudadanos externos a este territorio, como podría hacerlo un teatro, un cine, el comercio o una estación de metro. Simplemente hay un vacío urbano, poblado de viviendas destinadas a 'los otros'.

Considerando entonces esta estigmatización, el párroco de la iglesia, padre Gallizzi, solicitó a la Municipalidad cambiarle el nombre al barrio: pasar de llamarse ZEN -que, de hecho, no es un nombre, sino una sigla- a tomar el nombre de la iglesia presente en el territorio. Así fue que pasó a llamarse 'San Filippo Neri', aunque sus habitantes, los medios de comunicación y en general la entera ciudad lo continúe llamando por su sigla original. 
Sin embargo, más allá del cambio de nombre son nulas las intervenciones que el gobierno local o nacional han realizado por el barrio, dejándolo en un absoluto estado de abandono.

Es evidente que desde el exterior la percepción del ZEN es unificada y compacta, sin embargo, no es tan clara la percepción que tienen los propios habitantes de su barrio. Por ello, esta investigación ha querido indagar en esa percepción, para identificar la imagen que tienen los habitantes del espacio urbano que habitan cotidianamente.

\section{La percepción del espacio urbano}

La ciudad y todo lo que ella incluye no pueden ser considerados en sí mismos sin tomar en cuenta el contenido, valor o lecturas que se hacen de estos objetos urbanos, las trayectorias (Certeau, 2012) que se realizan en el interior de la ciudad constituyen el contenido mismo del territorio (Ragonese, 2006). Es decir, la ciudad no puede considerarse como un espacio inocuo u objetivo, sino que, al contrario, está cargada de sentido subjetivo y adquiere un valor simbólico (Caravedo, 2012).

"Si pensamos en los espacios urbanos de lo público, las plazas, las carreteras, los monumentos, en la ciudad de la materialidad, veremos que siempre habrá un imaginario que la construye y acompaña. Los imaginarios marcan la ciudad $y$, por ende, la manera de percibirla, de moverse en ella y habitarla" (Márquez, 2007, p. 80).

Se reconoce que los espacios urbanos, siendo físicos, no tienen el mismo valor para todos sus habitantes. Entonces, lo que adquiere sentido "no es el espacio material en sí mismo, sino, más bien, el espacio simbólico que se crea entre los que habitan en ellas" (Caravedo, 2012, p. 8), conformándose una relación dialéctica entre la dimensión física y la dimensión subjetiva asociada a esta.

Es más, es posible que entre imaginarios personales de la ciudad exista una distancia, conformando imaginarios diversos e incluso incongruentes entre ellos, que dan cuenta de los distintos modos de habitar, observar, de sentir el territorio. Esta distancia entre las formas de percibir la ciudad se debe a que la imagen que nos formamos se origina en la información que nos llega desde nuestros sentidos, la cual es tan variada como las formas en las cuales nosotros percibimos aquella información. "La percepción es solamente una respuesta de los sentidos a los estímulos externos, una actividad propositiva en la cual son seleccionados y registrados ciertos fenómenos y, en cambio, otros son bloqueados. Mucho de aquello que percibimos tiene un valor para nosotros y propicia algunas satisfacciones culturales" (Tuan, 1980, p. 4).

El ambiente sugiere distinciones y relaciones, el observador -con gran habilidad y propósitos específicos- selecciona, organiza y atribuye significados 
a aquello que observa. "La imagen así desarrollada, ancla, limita y acentúa aquello que es visto, mientras esa misma es puesta a la prueba respecto a la percepción, filtrada en un proceso de constante interacción" (Lynch, 2010, p. 28).

Por esta razón, dos personas no perciben de la misma manera la misma realidad. La imagen ambiental puede variar notablemente de un observador a otro, no obstante, según Lynch (2010), si los observadores son agrupados por categorías -de edad, sexo, ocupación, etc.- pareciera que entre los miembros de un mismo grupo existe un relativo acuerdo en relación a la imagen ambiental percibida. Aunque todos los seres humanos tengamos órganos de los sentidos relativamente similares, el modo en que las capacidades son usadas o la forma en la que interpretamos la información que llega a nuestros sentidos pueden variar radicalmente de una persona a otra.

El término topofilía considera los lazos afectivos de los seres humanos con el medioambiente, ya que las personas se relacionan afectivamente con los lugares y/o el ambiente físico, entonces, lo que implica y genera un lugar para/en una persona va a depender de la experiencia precedente de la misma (Tuan, 1980). Desde la semiología se menciona que los objetos, gestos e imágenes no tienen un significado en sí mismos, sino más bien serían funciones-signos que expresarían la funcionalización recurrente asociada al objeto. "El significado no es una 'cosa', sino una representación psíquica de la 'cosa'" (Barthes, 1964, p. 46). El sentido de los objetos urbanos no está ligado a un objeto como etiqueta (Pellegrino \& Jeanneret, 2006). El significado encuentra su pertinencia en la acción y el uso asignado al objeto.

Según Tversky (2003), para entender en las concepciones humanas del espacio debemos considerar no solo las cosas en el espacio sino especialmente las relaciones cualitativas entre el espacio y las cosas. En la conformación mental del espacio existirán ciertos elementos o cosas y relaciones espaciales que se seleccionan como relevantes dependiendo de su funcionalidad. "El mecanismo cognoscitivo central que entra en funcionamiento es la percepción, la cual trata de diferenciar entre lo propio y lo ajeno, y -en consecuencia- entre lo válido y no válido" (Caravedo, 2012, p. 9). Se trata entonces de significaciones que traducen procesos de apropiación de sentido (Bonoro, 2006).

Entendiendo que el espacio urbano es representado por los habitantes en una dimensión propiamente emotiva y subjetiva, nuestro interés es conocer la relación entre la forma urbana y la representación mental que tienen los habitantes de su propio barrio, a través de mapas mentales o perceptivos, que son la expresión gráfica de aquella idea que subjetivamente nos formamos, es más, para actuar efectivamente en el espacio, las personas necesitan una representación mental del mismo, una carta de navegación diría Francisca Márquez (2007). 
Los mapas mentales se han utilizado por diversas disciplinas, desde la semiótica, la geografía, la sociología urbana hasta la sociolingüística (Würth, 2014). Variadas son las investigaciones a nivel internacional respecto de los mapas cognitivos (Tversky, 2003; Würth, 2014, sin embargo, respecto de los mapas perceptivos son menores los trabajos realizados.

En este punto se hace relevante distinguir entre percepción y cognición. Reservamos el término percepción para el proceso que ocurre debido a la presencia de un objeto y que da lugar a la aprehensión inmediata de ese objeto por uno o más de los sentidos. Está estrechamente relacionada con eventos en el entorno inmediato. La cognición, en cambio, no necesita estar vinculada con el comportamiento inmediato y, por lo tanto, no necesita estar directamente relacionada con nada que ocurra en el ambiente próximo (Downs \& Stea, 1973). Entonces, dado que el presente estudio se interesa por la relación con los objetos en un ambiente próximo, es que se hace referencia a procesos perceptivos y no cognoscitivos.

Si bien en el presente documento se enfatiza en distinguir entre percepción y cognición, no se considera pertinente diferenciar entre mapas mentales y mapas perceptivos, que en este documento pueden ser utilizados como sinónimos, ya que en ambos casos representan una expresión gráfica de la imagen ambiental. Sin embargo, nuestro enfoque se diferencia de los trabajos de, por ejemplo, Marta de Alba (2004), quien utiliza mapas mentales para estudiar las representaciones cartográficas de la ciudad de México en general, que incluye zonas que pueden ser ajenas a los sujetos. En tanto, los mapas perceptivos son representaciones cartográficas del espacio urbano habitado, con el que se entra en directa interacción dialógica entre el espacio arquitectónico y sus residentes. Este proceso dialógico ocurre en el desarrollo de la vida cotidiana de los habitantes en relación con su espacio inmediato -su barrio- y constituye la base para la formación de mapas perceptivos.

\section{Metodología}

Los resultados presentados hacen parte de un estudio etnográfico realizado en el barrio entre abril del año 2012 y noviembre del año 2013. Se realizó observación participante durante más de un año, acompañado algunas veces de entrevistas etnográficas. En total se realizaron 114 notas de campo de cada una de las observaciones, 25 entrevistas a residentes del barrio y 18 mapas perceptivos, de los cuales se exponen solo algunos ${ }^{6}$.

6 Todos los nombres de los entrevistados indicados han sido modificados para mantener la confidencialidad. El nombre asignado ha sido el que los mismos entrevistados han seleccionado. 
La incorporación de los mapas perceptivos se realizó durante el transcurso investigativo, ya que se evidenció problemático conocer la percepción del espacio urbano. Frecuentemente los entrevistados no sabían cómo responder a las preguntas, o bien, tenían dificultades para reflexionar en relación a su propio barrio. Por una parte, sabían perfectamente cuál es la percepción externa en relación al barrio, ya que han vivenciado la discriminación que esta trae aparejada, pero tenían dificultades al momento de dar cuenta de su propia percepción sobre él.

Frente a las dificultades de expresión verbal, se recurrió a los mapas perceptivos, una técnica innovadora de investigación social cualitativa que implica solicitar a los entrevistados realizar un dibujo de su propio espacio urbano (Gardini, 2011). De este modo se toman en consideración las representaciones espaciales que emergen en la construcción de los mapas dibujados por los habitantes de este espacio de relegación. Cuando una persona habla acerca de -y sobre todo cuando dibuja- el espacio en el que habita, elige representar ciertos lugares. Generalmente aquellos que frecuenta y con los que tiene una relación topofílica. Consecuentemente, aquellos elementos no identificados, pero conocidos por el investigador, entregan información sobre aquello con lo que no tienen una relación cotidiana, de este modo, a través de los mapas perceptivos, el espacio urbano es representado por los habitantes en una dimensión propiamente emotiva y subjetiva, expresando el modo en que el barrio es vivido.

El dibujo de los mapas perceptivos o mentales es una técnica muy utilizada para observar las representaciones del espacio urbano. Diversas disciplinas han recurrido a ellos, especialmente la geografía, la psicología ambiental o la sociología, pero también la semiótica o la lingüística. "Los dibujos y los soportes gráficos son métodos empleados frecuentemente en las investigaciones sobre las representaciones sociales, pues facilitan la expresión de imágenes y permiten estudiar ciertos objetos de representación donde la dimensión no verbal es esencial" (Abric, citado en Alba, 2004, p.118). Consideramos que los dibujos de los mapas mentales constituyen un aporte significativo a la investigación social, pues proyectan libre y espontáneamente una imagen de la ciudad que puede evidenciar los elementos constitutivos y organizadores de la representación espacial (Alba, 2004).

Asimismo, para que una imagen sea útil para orientarse espacialmente, aquella debe ser comunicable a otros, por lo que a los entrevistados se les solicitó realizar un mapa que permitiese a una persona externa moverse por sí solo en el interior del barrio ZEN. El trazado del mapa se hizo una vez finalizada la entrevista y aportó resultados significativos, ya que su realización implicó no solo la dimensión visual del dibujo, sino también la narración que acompañó su realización. 


\section{Resultados}

Frente al objetivo de identificar la forma en que los habitantes del barrio ZEN perciben su propio espacio, los resultados se expresan, en primer lugar, en cuanto a la relación que se percibe desde el barrio con respecto a la ciudad. Sucesivamente el análisis se centra en el interior del proprio barrio, centrándose primero en las evidentes fracturas en su interior, para finalizar con la identificación de ciertos lugares que cobran mayor relevancia en el barrio, ya sea porque constituyen un punto de encuentro entre distintas zonas o bien porque es un espacio altamente frecuentado.

\section{VÍNCULO BARRIO-CIUDAD}

Frente al cuestionamiento vinculado a la forma en que los habitantes de este espacio relegado perciben su propio barrio, se evidencia una clara diferencia en la percepción entre personas con distinto nivel de escolaridad: los entrevistados con mayor nivel de escolaridad imaginan su barrio en una manera completamente diferente a los residentes con escasa formación escolar. Los primeros dibujan su barrio demarcando claramente los límites del encierro y en su interior distinguen algunos centros principales (figura 1).

Esta percepción puede entenderse debido a que en el interior del barrio hay solo una escuela básica y media, pero para estudiar en el liceo los residentes del ZEN deben salir del barrio, lo cual puede haberles dado la posibilidad de tomar conciencia de la fragmentación del barrio en relación a la ciudad de Palermo.

Al contrario, los entrevistados que tienen un nivel escolar bajo -ya sean adultos o jóvenes- mostraron serias dificultades para representar su propio barrio. Frente a la solicitud de dibujar, casi todos esbozaron 'el camino a casa' (figura 2) y, mientras explicaban su dibujo, justificaban la escasa información a través de un desconocimiento del barrio, del hecho de no salir nunca de casa, de conocer solo a los parientes y a los vecinos de su propio edificio.

Esta categoría de entrevistados representa en los mapas los puntos del barrio que frecuentan y conocen. Dibujan su propia casa y, a partir de eso, las calles que llevan a la iglesia, a la escuela, a la farmacia, al centro comercial.

Es relevante mencionar que en los dibujos de los residentes con una menor educación formal no son representados límites barriales, es más, muchos de ellos ni siquiera dibujan el barrio completo, sino más bien solo algunas calles y puntos principales. Es como si se reconociera que el barrio es más amplio de lo que se plasma en el dibujo, pero las otras partes del barrio no son significativas, porque no han desarrollado aquella relación dialógica necesaria para que sea incluido en una representación gráfica. No es percibido, por lo tanto, no es incluido en el mapa. 


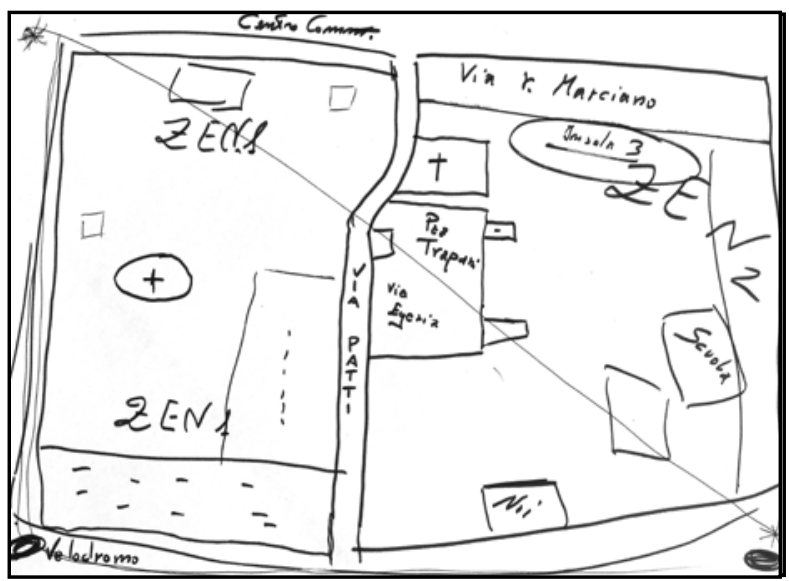

Figura 1. Mapa perceptivo dibujado por Giuseppe, 28 años, residente ZEN 1, educación superior.

Es necesario aclarar que esta categoría de entrevistados, con baja o nula formación escolar, está compuesta casi completamente por mujeres adultas y dueñas de casa, que escasamente han trabajado fuera de su hogar y que llegaron en la infancia a vivir al ZEN, por lo tanto, sin haber continuado los estudios y sin trabajar fuera de casa, las razones para salir del barrio se reducen significativamente, lo que permitiría comprender su visión extremamente local y reducida del espacio urbano habitado.

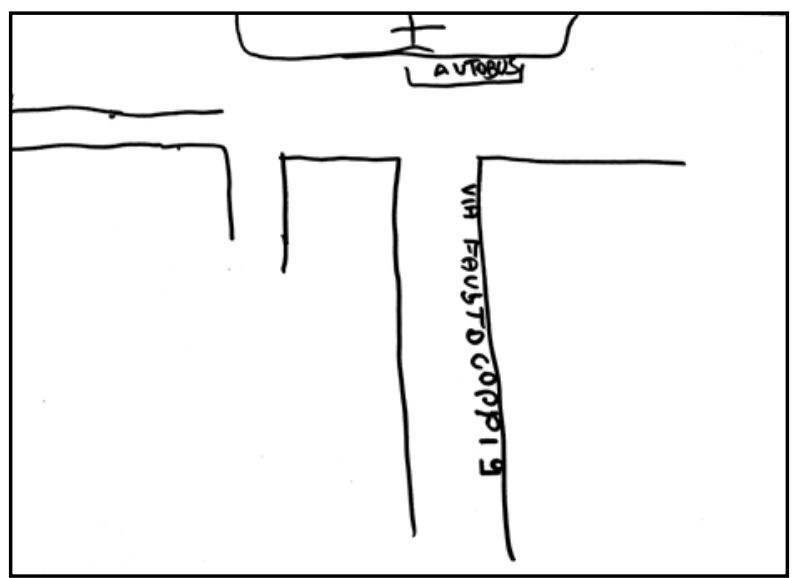

Figura 2. Mapa perceptivo dibujado por Katia, 37 años, residente ZEN 2, educación básica.

\section{FRAGMENTACIÓN MULTI-ESCALAR}

Al interior del barrio ZEN se distinguen claramente ciertas fronteras que dividen el espacio en microcosmos, transformándolo en una fragmentación multi-escalar tipo muñeca rusa, es decir, donde la fragmentación externa contiene en su interior otras formas de separación.

El primer nivel de aislamiento es el mismo barrio, cerrado y desconectado del resto de la ciudad. Esta fragmentación se representa físicamente en la 
estructura vial de circulación rápida que lo circunda y lo deja aislado, encerrado por estas calles. De hecho el anillo vial constituye una isla, produciendo una exclusión a priori (Sciascia, 2012). Francesca, una profesora de la escuela, menciona:

"Este es el único barrio que está delimitado por una cinta de muros, y esto ya es un elemento símbolo, ¿no? Ellos están al interior de este muro, más allá del muro no se puede ir, como dicen ellos, 'a Palermo', porque para ellos es como si viviesen en otro país, en otra ciudad. [...] El barrio está aislado, marginado del contexto ciudadano" (Francesca, profesora de la escuela).

Elena, residente histórica de ZEN 1 y empleada en una de sus asociaciones, respondiendo a la solicitud "ipodrías dibujar tu barrio?" nos representa un espacio homogéneo y cerrado. Traza una línea que circunda su barrio y lo aleja del resto del espacio urbano. Aquello que hay fuera del mismo pareciese no existir, o bien, no ser significativo (figura 3).

Efectivamente el barrio se encuentra cercado por un anillo vial, pero en su interior está subdividido en tres partes: Borgo Pallavicino, ZEN 1 y ZEN 2. Borgo Pallavicino es un espacio de vivienda social de los años cincuenta con edificios bajos de dos o tres pisos y un pequeño jardín en la entrada. ZEN 1 , en cambio, está constituido por grandes edificios de 10 pisos. Los edificios de ZEN 2 son viviendas sociales conformadas por la repetición geométrica de edificios rectangulares llamadas insulae, que constituyen la base arquitectónica del barrio.

En este sentido, en la distinción entre ZEN 1 y ZEN 2 radica el segundo nivel de diferenciación, ya que se entienden como dos entidades unificadas burocráticamente, pero distintas en la práctica. La mencionada conformación inicial del barrio ha tenido un impacto fundamental en la actual distribución del mismo, el cual prácticamente se encuentra dividido en dos partes, que corresponden a las dos etapas de construcción. En la primera parte del barrio, ZEN 1, se cuenta con diversos servicios: una sede del banco, correos, muchas panaderías, cafés y locales comerciales varios, así como con dos escuelas y un consultorio ginecológico. Separando las dos etapas del barrio se encuentra un terreno que debería ser una plaza, pero que no es más que un espacio de tierra, que los jueves se convierte en el mercado de frutas y verduras. Esta plaza y los edificios que la rodean constituyen el centro comercial del barrio y, al mismo tiempo, el límite entre ZEN 1 y ZEN 2, separados -o conectadospor el espacio dedicado a la iglesia. En la figura 4 se vislumbra claramente aquella distinción entre ambas zonas del barrio, separadas por una vía que se extiende a lo largo y a partir de la iglesia ${ }^{7}$.

7 En los mapas perceptivos, la palabra chiesa representa a "iglesia". 


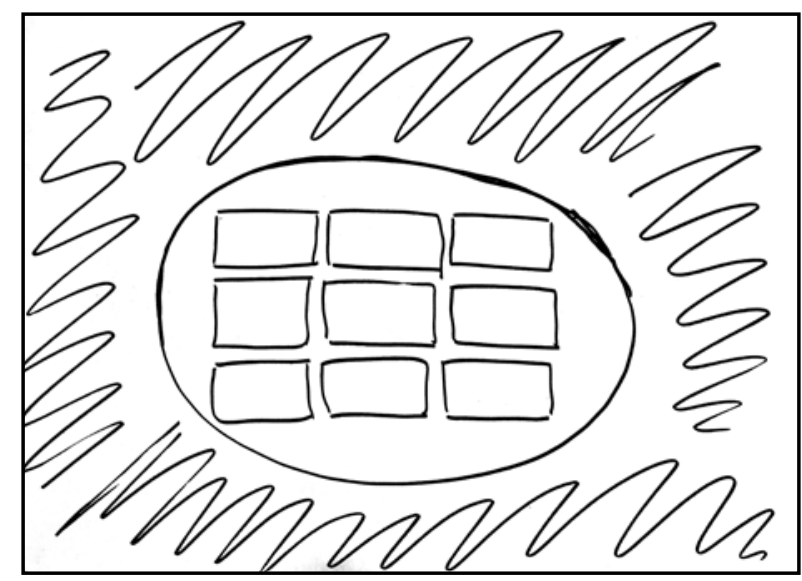

Figura 3. Mapa perceptivo dibujado por Elena, 26 años, residente ZEN 1.

Muy similar es el mapa de la figura 5, que además utiliza el color verde para distinguir claramente el ZEN 1 del ZEN 2, incluyendo además una flecha hacia la segunda parte del barrio y agregando la palabra "degradado". Aunque en el mapa de la figura 3 no se identifique la línea divisoria entre ambas zonas y solo se dibuja la iglesia en el centro, la utilización del color verde destaca la distinción.

Efectivamente, esta división no solo responde a periodos de construcción, sino que también tiene otros matices. En ZEN 2 los servicios -públicos o comerciales- son mucho más escasos, y sobre todo son fuera de lo legal, ya que al no tener las viviendas asignadas, ningún servicio ni impuesto

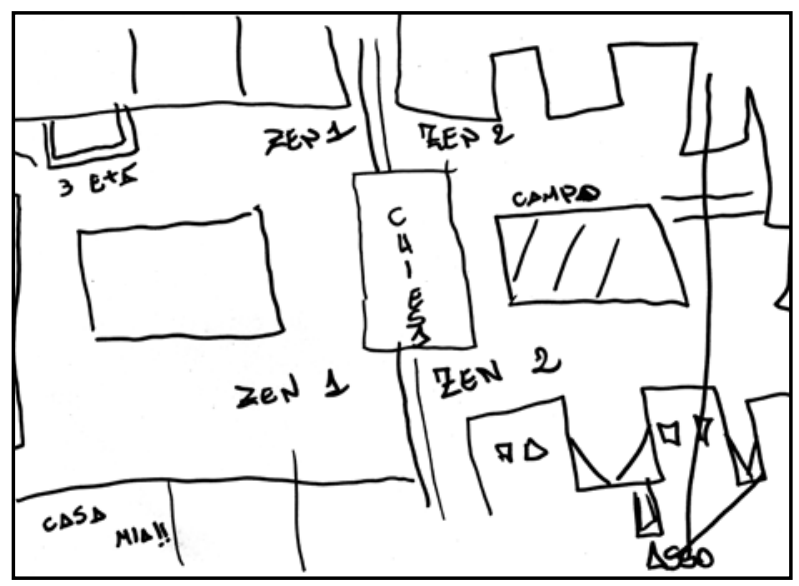

Figura 4. Mapa perceptivo dibujado por Andrea, 18 años, residente ZEN 1.

es pagado. Es una forma precaria de 'arreglárselas', abrir las puertas del garaje y destinarlo a cualquier tipo de economía que pueda ayudar con los gastos familiares.

"Las imágenes [externas] son evidentes, o sea de un barrio en el cual entrando no sabes qué cosa te pueda suceder, como si aquí estuvieran todos armados o caminaran con los cuchillos listos para robarte, listos para hacer quizás qué cosa. Pero viviendo dentro te das cuenta que, efectivamente, ZEN 1 y ZEN 2 parecen realidades completamente diferentes, que ZEN 1 parece una realidad residencial con tranquilidad, porque es raro que suceda algo como automóviles robados, autos quemados y esas cosas. En cambio si entras al ZEN 2, ya solo en cuanto 
entras ves y te das cuenta de la degradación estructural y arquitectónica, te das cuenta también de la basura, te das cuenta de esos automóviles quemados que continuamente cambian". (Elena, 26 años, residente ZEN 1)

Es relevante mencionar que solo aquellos residentes de la primera zona del barrio dibujan ZEN 1 y ZEN 2, identificando la línea divisoria entre ambas zonas -como ya se ha visto en el mapa de la figura 2- mientras que en el mapa de la figura 3 se utiliza la iglesia como punto de separación. Se reconoce entonces, por parte de los habitantes de ZEN 1, la existencia de aquella zona más degradada, pero diferenciándola de 'mi barrio'.

No obstante, aquellos residentes de la segunda zona, al dibujar su propio barrio consideran solo ZEN 2, ya que la primera parte del barrio, ZEN 1 , no está considerada dentro de su espacio de acción cotidiana, no es significante. De hecho, todos los entrevistados de la segunda zona, al solicitarles dibujar su propio barrio, comienzan a dibujar la iglesia (figura 6). Esta última cumple la función de frontera desde la cual se extiende su espacio cotidiano.

El tercer nivel de aislamiento lo constituyen las insulae, unidades edificadas rectangularmente ${ }^{8} \mathrm{y}$ formadas por líneas de tres pisos de viviendas. Cada insulae está dividida en tres diferentes espacios: dos largos pasillos elevados del suelo, y un pasillo central donde se permite el paso de automóviles. En los dos lados más angostos de la insulae se erigen dos altas torres de 6 pisos (Sciascia, 2012).

Las insulae son llamadas 'pabellones' por los residentes, como los pabellones de una cárcel, y se caracterizan por un sentido del anonimato, ya que desde su planificación vienen denominadas solo con números y letras. El hecho de no contar con un nombre oficial no ha impedido que los residentes hayan renombrado sus pabellones en base a sus características: años atrás existían los 'pabellones quemados', identificando a la insulae 3E que se quemó y quedó en esa condición por mucho tiempo. Años después esta fue reestructurada y hoy le dicen 'los pabellones nuevos'.

En el proyecto original las partes bajas de los edificios -insulae- estaban destinadas a bodegas, pero hoy muchos de esos espacios están convertidos en pequeños almacenes, servicio de lavado de automóviles u otro tipo de actividades en el marco de la economía informal. La estructura de las insulae produce lo que su nombre evoca, es decir, un sucesivo aislamiento de los habitantes que reproduce un "encierro multiescalar: la casa, el pabellón, la ínsula, el barrio, la ciudad" (Fava, 2008b, p. 83).

Así, el cuarto y último nivel de aislamiento es la propia casa, no obstante esta es una experiencia

De 64.8 metros de ancho por 182.3 metros de largo. 


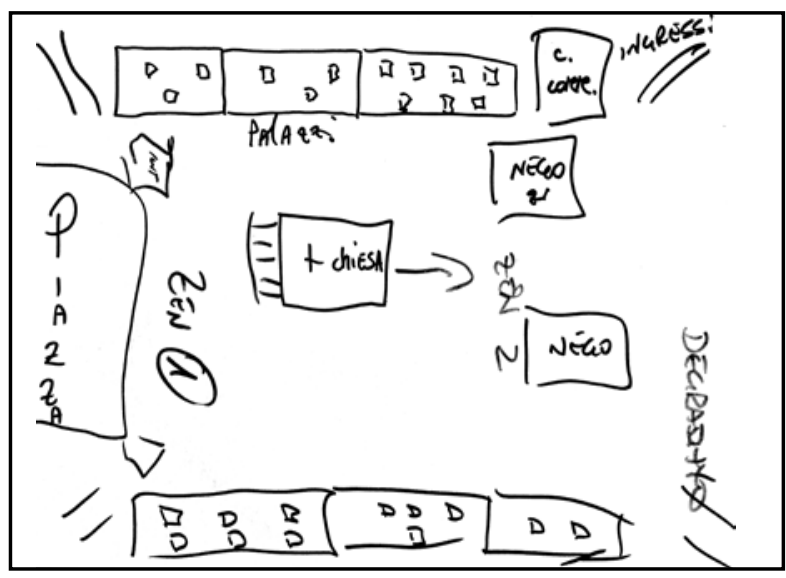

Figura 5. Mapa perceptivo dibujado por Giuseppe, 18 años, residente ZEN 2.

casi exclusivamente feminizada. Las mujeres no solo salen de casa escasamente, sino que cuando lo hacen, debe ser por alguna razón familiar que justifique la salida -ir a buscar los niños al colegio, comprar algo para preparar la alimentación familiar-, situación que se agudiza si consideramos que la compra de enseres y alimentos cotidianos se hace, frecuentemente, al carro que atraviesa el barrio y a través de un cesto que las mujeres bajan con un cordel, por lo que no tienen la estricta necesidad de salir a comprar: son verdaderas presas dentro de su propia casa (Zenteno, 2016).

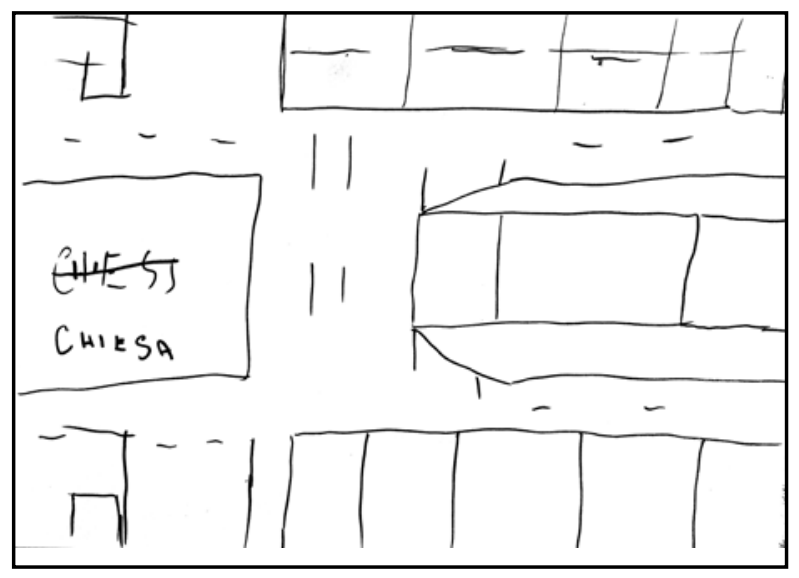

Figura 6. Mapa perceptivo dibujado por Salvo, 48 años, residente ZEN 2.

\section{ANÁLISIS SEGÚN LA PRESENCIA E IMPORTANCIA DE CIERTOS OBJETOS}

El primer elemento que aparece al analizar los mapas perceptivos es que la presencia de la iglesia es transversal en todos los mapas realizados, indicando que esta es una institución consolidada en el barrio, tanto a nivel religioso como a nivel arquitectónico: el edificio eclesiástico construido en el centro del territorio, conectando ambas zonas del barrio, se ha transformado en su principal punto de referencia. 
Los residentes históricos del barrio están vinculados afectivamente a la iglesia. Durante el primer periodo no existía una estructura arquitectónica que acogiera a los fieles y las misas, por lo que los sacramentos se realizaban en un jardín de ZEN 1. Hoy a aquel jardín se le llama "iglesia madre", ya que se lo considera un hito inicial de la vida religiosa del barrio y aún se utiliza en algunas ocasiones durante el periodo estival. Años después, con el aporte de los fieles, se construye la actual iglesia. El hecho de haber contribuido a financiar su construcción, explica aquella importancia que le atribuyen al edificio.

Por otro lado, es relevante recordar que Sicilia es una región profundamente católica, más aún en los barrios populares como el estudiado (Dino, 2010). La relación entre la institución eclesiástica y el barrio se consolida oficialmente en el momento en que el Comune de Palermo decide cambiar el nombre de Zona Espansione Nord (ZEN) a San Filippo Neri, de este modo, el barrio registra administrativamente el nombre de la iglesia que alberga.

La estructura arquitectónica de la iglesia, construida en el centro entre ZEN 1 y ZEN 2, adquiere una doble función: por un lado es el punto de encuentro entre ambas zonas, pero al mismo tiempo funciona como elemento de distinción, de separación. La iglesia es el punto donde se cruzan las dos realidades que viven en el barrio. Pero, como ha sido antes mencionado, para quien vive en la segunda parte de este, su espacio de referencia comienza a partir de la iglesia.

Así, la importancia de la estructura eclesiástica como punto de referencia es clara. La iglesia es parte de la vida cotidiana y, en consecuencia, está al centro de relatos y trazados. Por otro lado, como mencionamos, puede llegar a constituir un elemento de unificación del espacio para ciertos habitantes. Eso es evidente en representaciones como el mapa perceptivo de la figura 7, en el cual pareciera que todas las calles llevan a la iglesia.

Es interesante cómo al momento de comenzar a dibujar muchas veces las personas comienzan desde la iglesia y desde ahí continúan con el resto del barrio. Incluso en algunos dibujos la iglesia ocupa un gran espacio del mapa. Otros, parecen dibujar únicamente la iglesia como si quisieran expresar que es "el" punto de referencia en su barrio.

Importante es mencionar que todos los dibujos realizados son la respuesta a la solicitud: ime podría dibujar su barrio? Algunos han dibujado un mapa incluyendo información relevante; otros, los elementos más significativos para ellos. Sin embargo, se debe reconocer que la estructura arquitectónica de la iglesia no es neutra. Si se observa, se nota que el antejardín y la puerta de entrada de la iglesia se abren en dirección hacia ZEN 1, es decir, la zona más dinámica del barrio, hacia donde la iglesia muestra su lado más bello, con un gran jardín que constituye el único espacio verde en todo 


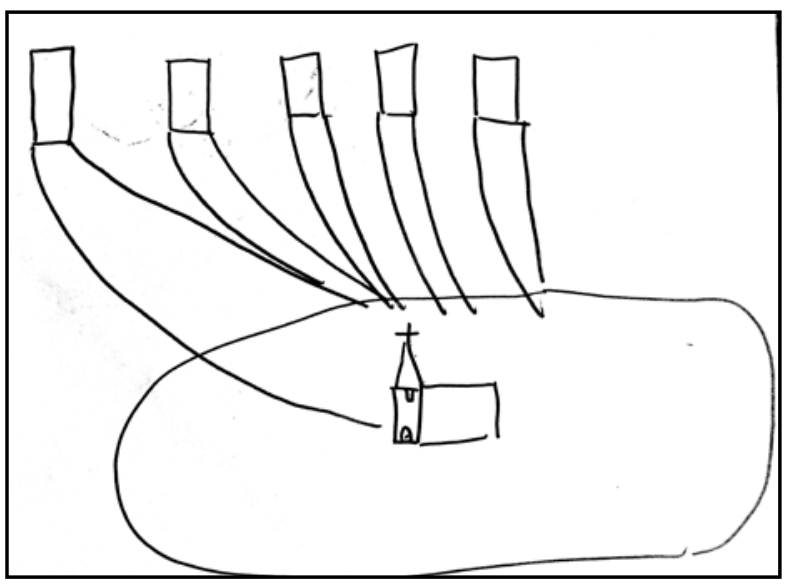

Figura 7. Mapa perceptivo dibujado por Giuseppa, 48 años, residente ZEN 2.

el barrio. Mientras que la parte trasera de la iglesia, aquella donde no hay más que una pared, es el lado que da hacia ZEN 2. Es como si mostrara su lado más cerrado hacia la segunda etapa del barrio, aquella más degradada.

A pesar de todo, la iglesia es el principal punto de referencia para los habitantes de ZEN 2, ya que, además de la escuela, el barrio cuenta únicamente con viviendas. Al contrario, los residentes del ZEN 1 dibujan otros elementos como el velódromo y algunos almacenes.

De hecho, en los dibujos realizados por mujeres está siempre presente la escuela, en segundo lugar

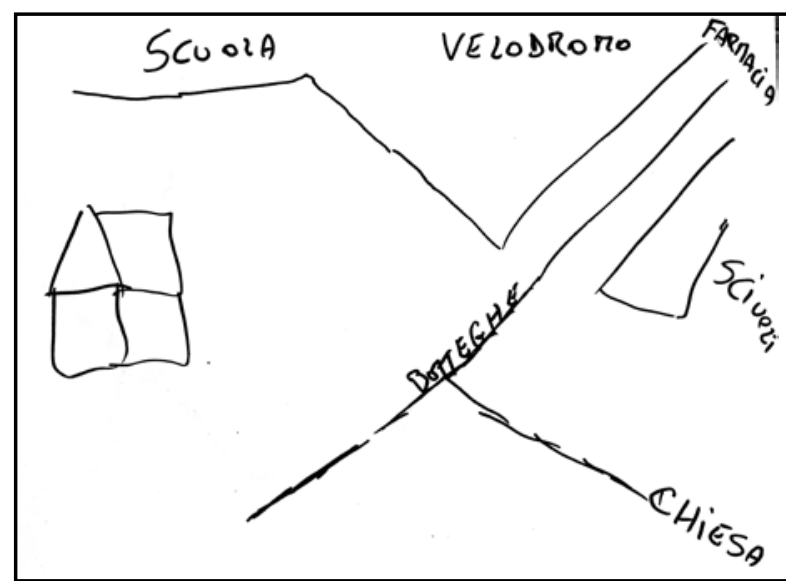

Figura 8. Mapa perceptivo dibujado por Mimma, 43 años, residente ZEN 2.

de importancia después de la iglesia. La escuela es un lugar altamente apreciado por las madres, que llevan cotidianamente a sus hijos a ella y para las cuales esta se vuelve un punto fijo en sus trayectorias diarias. También están presentes los almacenes del barrio, la farmacia (figura 8).

\section{LA MONTAÑA}

Otro elemento de referencia importante es $u$ montaruozzo $0^{9}$, ubicado en la calle que lleva a la escuela $y$, en consecuencia, en una zona de alto tránsito para los residentes del barrio (figura 10). En los planos iniciales del barrio este espacio correspon-

9 Del dialecto siciliano "la montaña". 
día a un parque, pero debido a que el barrio nunca ha sido terminado, quedó cercado de edificios, sin nada en su interior. Es un espacio contradictorio, porque está lleno y vacío al mismo tiempo: lleno de maleza, escombros, sillones viejos, trozos de automóviles quemados; y vacío porque, efectivamente, no hay nada útil ahí dentro. Los habitantes le llaman "la montaña", porque es tal la acumulación de basura y escombros que ha formado un cerro. A medida que pasan los años los residuos continúan acumulándose, los ratones se reproducen y los camiones que recogen la basura no se hacen cargo de un problema que no les pertenece ${ }^{10}$. Frente a tal escenario, las autoridades políticas no se han expresado. Entonces el único momento en que la basura desaparece es cuando su cuantía obliga a quemarla, sometiendo a quienes viven y circulan por el sector a respirar ese humo tóxico. En los mapas la montaña está presente como punto de referencia, como es posible verlo en el mapa de la figura 9: se dibuja la iglesia, seguido de la montaña, con distintos niveles para cerrar con una calle en medio de un punto, acompañado de la afirmación: "esta es mi casa".

La ironía es que en medio de este basural a cielo abierto, aún sobrevive un cartel -ya casi completamente cubierto por los arbustos y la basura- que dice: "Aquí será construido el Jardín de la civilización". Por otro lado, la función de este lugar en

10 Los camiones de recolección de basura recogen solo los desperdicios que están en los contenedores. No están obligados a recoger escombros.

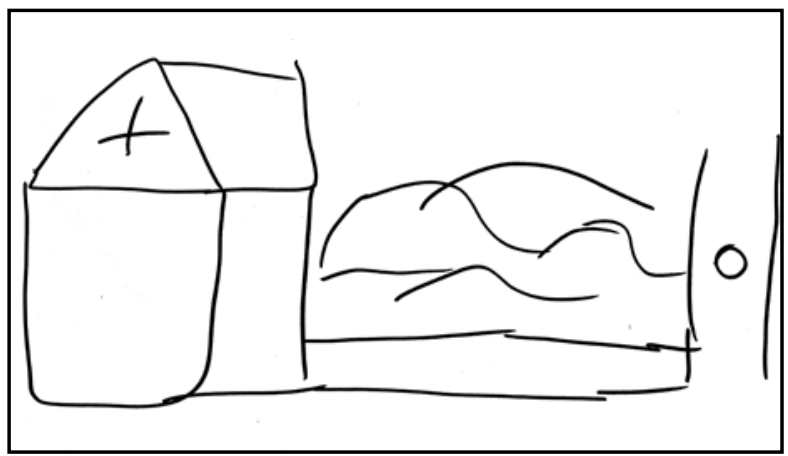

Figura 9. Mapa perceptivo dibujado por Salvezza, 40 años, residente ZEN 2.

el barrio es altamente compleja, porque participa en el desarrollo de la economía local, tanto de las actividades informales como ilegales: por un lado sirve para dejar los residuos de los artículos robados -especialmente partes de automóviles-, pero por la otra, como lugar de abandono de escombros. Así lo explica Francesco:

"Ahora se ha vuelto una zona donde se bota todo... lo que da asco, por eso no se avanza. Y es que si no hay trabajo -y tú que haces trabajos, arreglos en casa, y tienes que pagar 100 a una persona para que te saque los escombros-, vengo yo y por 50 te saco los escombros. Tú me llamas a mí y no a ese que te cobra 100. Y isabes dónde los voy a botar? ¡Donde me sea más fácil!... Es así. Porque piensa, si tú me 


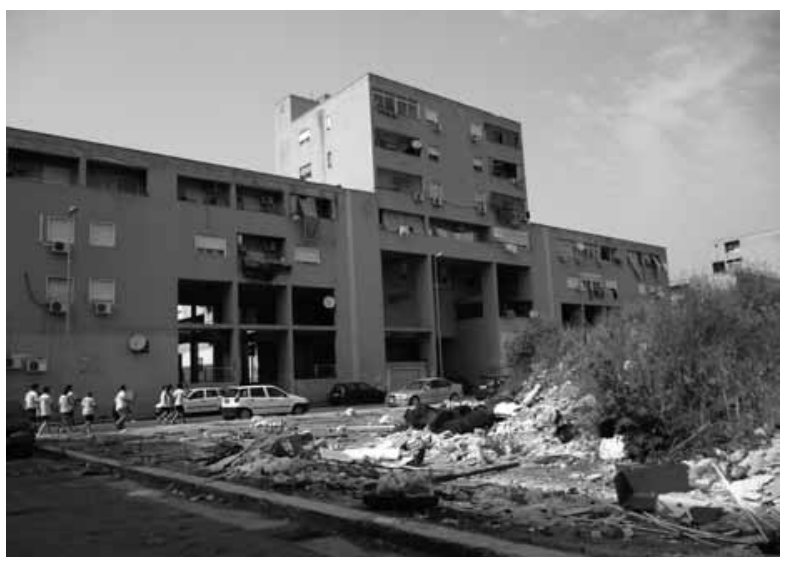

Figura 10. El jardín de la civilización, comúnmente llamado "la montaña".

Fuente: Archivo de Elizabeth Zenteno.

das 50 euros, ¿yo tendría que pagar la descarga que se paga 80 euros? Y piensa, con 10 euros yo pago el transporte, la bencina, mi jornada de trabajo y todo. Así es como se trabaja, se vive el día, y lo que sucede, sucede" (Francesco, 36 años, residente ZEN 2).

\section{EL CENTRO COMERCIAL}

De propiedad de Zamparini, el propietario de Palermo-Futbol Club, el centro comercial Conca d'Oro abre sus puertas el año 2010. Entre las justificaciones que se dieron para autorizar la construcción se menciona el potenciamiento del degradado barrio ZEN, a través de la generación de empleo. Sin embargo, en una construcción que se plantea como una fuente de trabajo para el sector, se instalan cajas con cobradores automáticos, eliminando así parte de la necesidad de mano de obra; además disponen de un servicio que transporta a los trabajadores desde sus viviendas hasta el centro comercial, el cual no entra al barrio mencionado.

Por otro lado, en la firma de la autorización de construcción del Centro Comercial, Zamparini se comprometía a ceder una parte del centro a servicios al ciudadano, como oficinas público-administrativas, que en algún modo servirían para mejorar la situación del barrio. Sin embargo, después de tres años de funcionamiento, esos servicios no han sido habilitados.

Sin embargo, no se puede decir que el centro comercial ha sido inocuo en la vida cotidiana de los habitantes del barrio. Ciertamente no ha modificado los hábitos de consumo, ni siquiera para los escasos habitantes que tienen un sueldo fijo al mes, ya que los precios del centro comercial están fuera de su alcance. Menos aún para la gran parte de la población que 'vive el día a día', por ejemplo, aquellas familias que dependen de los maridos y padre cuyo empleo es estacionar automóviles. Esas familias continúan comprando en pequeñas cantidades en los comercios locales y almacenes del barrio, que les permiten un pequeño crédito familiar.

Ahora bien, la instalación del centro comercial ha logrado un significativo cambio en la vida cotidiana del barrio, ya que ha venido a cubrir la falta de espacio público, de centros de entretenimiento, 
de encuentro juvenil, pero también el lugar donde llevar a los niños el fin de semana. Es frecuente escuchar a las madres decirle a sus hijos 'si te comportas bien, te llevo el sábado a la Conca d'Oro!'.

"Si no estuviera la Conca d'Oro no sé dónde estos niños podrían ir a jugar, porque la mayor parte de las chicas, las chicas de 14, 15 años, si tú en la tarde vas y paseas, como a veces lo hago yo [ves a esos] grupos de chicos que se van a la Conca d'Oro a darse una vuelta. Tienen su comitiva, que tienen una hora, dos horas, tú los ves dándose vuelta. Es que ese es un centro adecuado, aunque en la Conca d'Oro no haya nada, pero ya es algo más o menos, no es la misma cosa que estar en medio de la calle, allá te puedes tomar un helado, iqué sé yo! el café, el helado, el paseo, una cosa diferente. Aquí, en cambio, no hay nada... iqué cosa tienes para hacer aquí? ¿Qué? Bajas al pabellón y ¿qué haces? ¿Disfrutas del panorama? -ríe irónicamente-. Aquí estás siempre dentro de cuatro murallas y iqué haces? ¡Nada!”. (Giuseppa, 48 años, residente ZEN 2).

A partir de la instalación del centro comercial, los jóvenes han modificado sus lugares de encuentro y dispersión. Hoy ya no se reúnen con sus amigos en la esquina o al aire libre, sino en el centro comercial.

"Ahora tenemos el centro comercial, que es un recurso positivo. Yo creo que es positivo para el barrio porque permite a los chicos no estar solo en medio de la calle, sino que tener algo... Tú me puedes preguntar: ipero qué vas a hacer al centro comercial si no tienes un euro en el bolsillo? Pero para nosotros es una diversión, mirar los negocios aunque no te puedas permitir una cierta cosa, pero para nosotros ya es una cosa... donde te distraes... un pasatiempo". (Giuseppe, 18 años, residente ZEN 2)

Estos testimonios nos evidencian que, paradojalmente, el espacio privado ha tomado el lugar del espacio público, porque los habitantes lo consideran efectivamente un espacio público y lo viven en esa manera.

\section{Conclusiones}

La imagen desde afuera del barrio es clara y dominante. El estigma de vivir en el ZEN atraviesa todas las dimensiones de la vida en su exterior. Cuando sus residentes deben salir de su espacio, deben estar preparados para enfrentar el estigma homogeneizador que les adjudica los peores males de la ciudad. Como contraste, a lo largo de este documento hemos querido indagar en la percepción que tienen los habitantes de este barrio con respecto a su propio espacio urbano.

En primer lugar, es posible concluir que la percepción de aislamiento y fragmentación del propio barrio con respecto a la ciudad varía según el nivel de formación de los residentes. Como lo menciona Lynch (2010), a pesar de percibir los objetos de la ciudad de manera completamente subjetiva, es posible identificar ciertas tendencias en la percepción de determinadas categorías sociales: en este caso, 
si para las categorías sociales con mayor formación el aislamiento del barrio es evidente y queda expresado en los límites que dibujan en sus mapas al representar el propio barrio, para aquellas personas con una educación más baja, aquel aislamiento es inexistente, no aparece en sus dibujos, las fronteras no son percibidas.

Esta percepción diferenciada se relaciona con el nivel de educación, pero también con la posibilidad de establecer lazos sociales externos al barrio. Aquellos que han tenido una mayor movilidad urbana, que han salido frecuentemente del barrio, perciben la exclusión y la fragmentación del barrio con respecto a la ciudad, en cambio, aquellos que han tenido una relación menos frecuente con otras zonas de la ciudad no perciben el encierro y la fragmentación porque simplemente las otras zonas de la ciudad están vacías de significado, no entran en su marco de percepción del espacio urbano.

En segundo lugar, se evidenció que esta fragmentación no se limita únicamente a los bordes externos que encierran el barrio en sí mismo, sino que también en el interior del propio barrio existen fronteras invisibles que separan ZEN 1 de ZEN 2. Así, los mapas han permitido la expresión gráfica de los distintos niveles de fragmentación del barrio: la distinción entre barrio y su entorno, entre ZEN 1 y ZEN 2, entre pabellones y la propia casa como último nivel de encierro. Ha sido significativo visualizar gráficamente la intención de distinción de la primera parte del barrio respecto de la segunda, más degradada, a través de líneas divisorias que separaban ambas partes. Asimismo, los residentes de la segunda parte del barrio han representado aquella parte de su propio espacio urbano con el que han desarrollado una relación topológica, por lo que han incluido solo lo que consideran su barrio, ZEN 2.

Muchos de los dibujos de los residentes de ZEN 2 se han limitado a registrar las trayectorias cotidianas, en las que se expresan los lugares que tienen significación en sus vidas y los trascursos para alcanzarlos, y es que, como menciona Certeau (2012), en las trayectorias en donde se van construyendo las significaciones del espacio urbano.

Adicionalmente, más allá de las fracturas que pueda tener un barrio, en el análisis de la percepción del espacio urbano emergen ciertos lugares en su interior, a los que se les asigna un particular significado. Es así como aquellos lugares que tienen mayor significación, que tienen un lugar consolidado en la vida cotidiana de los habitantes, como la iglesia, que toma un lugar preponderante en los mapas; pero también nos permite identificar aquellos elementos de transformación, como es la inclusión del centro comercial en los mapas realizados por jóvenes, no así por los adultos.

En definitiva, la percepción del espacio urbano es un elemento extremamente personal y subjetivo en el cual se expresan diversas maneras de representar 
y de vivir el propio barrio. La percepción de los habitantes de su propio barrio varía según el nivel de escolaridad, si reside en la primera o la segunda parte del barrio u otras categorías sociales, como el sexo. Por lo tanto, la percepción del espacio urbano no depende de características objetivas, de etiquetas dadas por la forma arquitectónica del barrio, sino más bien de las dinámicas sociales que en él se van desarrollando y van adquiriendo significado para sus habitantes.

A nivel metodológico, la realización de los mapas perceptivos nos ha permitido conocer no solo la forma en que el barrio se percibe separado de la ciudad, sino también identificar aquellas estructuras del barrio que tienen mayor relevancia, porque tienen un significado en su vida cotidiana. Conocer los elementos presentes, como aquellos que no lo están, nos permite comprender sus puntos de vista y construir una representación del espacio a través de la formación de imágenes mentales específicas.

Así, los mapas perceptivos se han develado un útil instrumento de investigación cualitativo, que permite al investigador trabajar en contextos difíciles, más aún cuando expresarse lingüísticamente puede ser difícil para los sujetos de estudio. Es que la realidad social, en su alta complejidad, requiere del incentivo y la capacidad de explorar nuevas técnicas de investigación que nos permitan comprender los campos bajo estudio con nuevos enfoques. Por ello, la exploración metodológica puede solo enriquecer la práctica investigativa.

\section{Referencias bibliográficas}

Alba, M.d. (2004). Mapas mentales de la Ciudad de México: una aproximación psicosocial al estudio de las representaciones espaciales. Estudios Demográficos y Urbanos, 19(1), 115-143. https://doi. org/10.24201/edu.v19i1.1197.

Auge, M. (2008). Los no lugares. Espacios del anonimato, una antropología de la sobremodernidad. Barcelona, España: Gedisa.

Barthes, R. (1964). Elementos de semiología. Sao Paulo, Brasil: Cultrix.

Bonora, P. (2006), Città collage: conflitti di senso nei territori metropolitani, tra risemantizzazioni e travestimenti. En: G. Marrone \& I. Pezzini (Eds.), Senso e metropoli. Per una semiotica posturbana (pp. 73-76). Roma, Italia: Meltemi.

Caravedo, R. (2012), Las ciudades como espacios mentales y lingüísticos. Reflexiones sobre la variación diatópica del español. Orillas, (1), 1-17. Recuperado de http://orillas.cab.unipd.it/orillas/ es/01_02caravedo_rumbos/

Certeau, M.d. (2012). L'invenzione del quotidiano. Roma, Italia: Edizioni Lavoro.

Dino, A. (2010). La mafia devota. Chiesa, religione, cosa nostra. Roma, Italia: Laterza. 
Downs, R. \& Stea, D. (1973). Cognitive maps and spatial behaviour: Process and products. En R. Downs $\&$ D. Stea (Eds.), Image and environment: Cognitive mapping and spatial behavior (pp. 8-26). Chicago, USA: Aldine Press.

Fava, F. (2008). Lo ZEN di Palermo. Etnografia dell'esclusione. Milano, Italia: FrancoAngeli.

(2012). Insulae e corpi, testi e contesti: la poetica dell'abitare. En A. Sciascia (Ed.), Periferie e città contemporanea. Progetti per i quartieri Borgo Uliva e ZEN a Palermo (pp. 79-86). Palermo, Italia: Caracol.

Gardini, E. (2011). La trasformazione urbana dell'area dismessa ex-Italsider di Bagnoli. Uno sguardo sociologico sull'immagine dello spazio fisico in mutamento. Rassegna Italiana di Sociologia, 52(2), 229-252. https://doi.org/10.1423/34987.

Leone, N. (2008). Contraddizioni urbanistiche della Zona Espanzione Nord 2 a Palermo. En A. Badami, M. Picone, \& F. Schilleci (Eds.), Città nell'emergenza. Progettare e costruire tra Gibellina e lo ZEN (pp. 271-277). Palermo, Italia: Palumbo.

Lynch, K. (2010). L'immagine della città. Venezia, Italia: Marsilio.

Márquez, F. (2007). Imaginarios urbanos en el Gran Santiago: huellas de una metamorfosis. EURE 33(99), 79-88. https://doi.org/10.4067/ S0250-71612007000200007.

Mela, A. (2010), Sociologia delle città. Roma: Carocci.

Pellegrino, P. \& Jeanneret, E. (2006). Il senso delle forme urbane. En G. Marrone \& I. Pezzini (Eds.),
Senso e metrópoli. Per una semiotica posturbana (pp. 19-32). Roma, Italia: Meltemi.

Picone, M. (2012). Musica dissonante per lo ZEN. En A. Sciascia (Ed.), Periferie e città contemporanea. Progetti per i quartieri Borgo Uliva e ZEN a Palermo (pp. 95-102). Palermo, Italia: Caracol.

Ragonese, R. (2006). Mappe e rappresentazioni: città descritta e ritratti possibili. En G. Marrone \& I. Pezzini. Senso e metropoli. Per una semiotica posturbana (pp. 159-170). Roma: Meltemi.

Sciascia, A. (2012) Periferie e città contemporanea. Progetti per i quartieri Borgo Ulivia e ZeN a Palermo. En B. Todaro \& F. De Matteis (Eds.), Interventi sull'abitare pubblico. Linee guide per la riqualificazione dei quartieri innovativi dell'Italia centromeridionale. Roma, Italia: Prospettive.

Tuan, Y. (1980). Topofilia. São Paulo, Brasil: Difusão.

Tversky, B. (2003). Structures of mental spaces. How people think about space. Environment and behavior, 35(1), 66-80. https://doi. org/10.1177/0013916502238865.

Würth, M. (2014). Cartografías de la ciudad. Representación y estilización lingüística en mapas mentales de Buenos Aires. Boletín de Filologia, 49(2), 311-349. https://doi.org/10.4067/ S0718-93032014000200013.

Zenteno, E. (2016) La questione di genere nel quartiere San Filippo Neri, zen di Palermo: racconti etnografici. La Critica Sociologica, (197), 69-82. 